\title{
USE OF IMAGE BASED MODELLING FOR DOCUMENTATION OF INTRICATELY SHAPED OBJECTS
}

\author{
M. Marčiša*, P. Barták ${ }^{b}$, D. Valaška ${ }^{b}$, M. Fraštia ${ }^{a}$, O. Trhan ${ }^{a}$ \\ ${ }^{a}$ SUT in Bratislava, Faculty of Civil Engineering, Radlinského 11, 81005 Bratislava, Slovakia - (marian.marcis, marek.frastia, \\ ondrej.trhan)@stuba.sk \\ b 5S s.r.o., Páričkova 18, 82108 Bratislava, Slovakia-pbartak@hotmail.com, valaska@5s.sk
}

Commission V, WG V/2

KEY WORDS: Image Based Modelling, Timber Roof Truss, Spiral Staircase, Historical Furniture, Folk Costume.

\begin{abstract}
:
In the documentation of cultural heritage, we can encounter three dimensional shapes and structures which are complicated to measure. Such objects are for example spiral staircases, timber roof trusses, historical furniture or folk costume where it is nearly impossible to effectively use the traditional surveying or the terrestrial laser scanning due to the shape of the object, its dimensions and the crowded environment. The actual methods of digital photogrammetry can be very helpful in such cases with the emphasis on the automated processing of the extensive image data. The created high resolution 3D models and 2D orthophotos are very important for the documentation of architectural elements and they can serve as an ideal base for the vectorization and 2D drawing documentation. This contribution wants to describe the various usage of image based modelling in specific interior spaces and specific objects. The advantages and disadvantages of the photogrammetric measurement of such objects in comparison to other surveying methods are reviewed.
\end{abstract}

\section{INTRODUCTION}

Cultural heritage objects come in various shapes, sizes and materials (texture) and often they represent works of art with very irregular or ragged surface. In case of natural heritage objects (stuffed animals, preserved insect etc.), the complexity of shapes and variety of sizes is obvious too.

Depending on the object type, different kinds of documentation methods in terms of required accuracy, level of detail and form of output can be used. Due to the specific object's complex shape, mostly the non-selective automated technologies of geometric and radiometric information recording, such as image and laser scanning or their combination, are best fit for the task (Fassi, 2013).

In recent years, development of automated algorithmic image processing systems producing digital 3D object models reasonably improved possibilities of computer vision methods usage for tasks where photogrammetry methods were previously non-effective or not applicable altogether. The advantages of photogrammetric methods over laser scanning are evident: higher diversity in surface/terrain data acquisition (aerial too) (Pavelka, 2014), superior and precise texture information, arbitrary object size (from millimeters to hundreds of meters), theoretically unlimited detail of model, lower hw/sw cost. On the other hand, laser scanning does a better job at taking in outliers, minimizing errors, representing object shape and at addressing the model deformations. Despite of all that, there are objects of such specific shapes and texture, that a tailored scanning and processing approach is in order. Our paper deals with image based modelling applied to atypical, intricately shaped objects that won't pass the image scanning constraints and where the use of other measurement techniques would be non-effective or impossible.

\section{SUBJECT: HISTORIC FURNITURE}

Scanned objects were 7 pieces of rococo originals from around 1760 found in state collections/repositories in Austria and Hungary ( 2 desks, 1 sofa, 2 chairs, 1 stool +2 marble desktops), (Figure 1,2). Some objects were heavily golden plated and all were in a pre-renovation state (some chairs without upholstery). All had to be scanned on site in a regulated environment and in a limited time window.

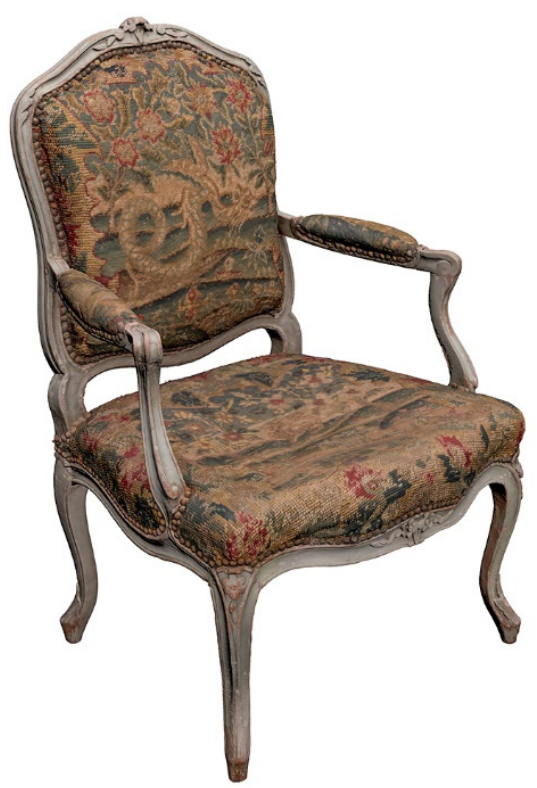

Figure 1. A historic chair with arm rests - 3D model. 


\subsection{Preparations and technique}

A special diffuse light tent was utilized on site. No major manipulation with objects was possible, only qualified personnel was allowed to handle the furniture in a protected environment. Some surfaces required a tailored lighting in order to minimize reflections.

The two marble table tops were not fixed to the frame thus were removed in order to properly scan the whole wooden frame. A total of $4,200 \mathrm{~W}$ of lighting output was used to generate a controlled diffuse lighting conditions.

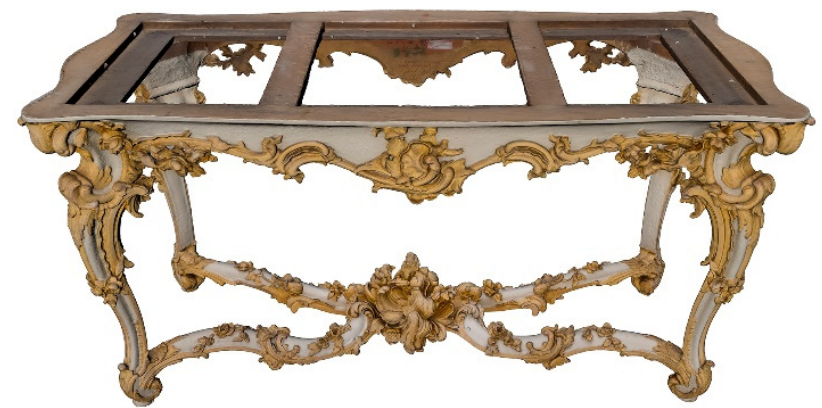

Figure 2. 3D model of the original rococo desk.

\subsection{Scanning and processing}

Scanning was carried out manually in a pre-designed scanning pattern using hi-res DSLR cameras (i.e. Canon $5 \mathrm{D}$ MkIII) in the tent. The scanning pattern was developed for this scanning project only using some test objects and in its final form contained two major scanning envelopes following the surface in a semi-constant object distance and spacing.

For some shots the power output of each lamp was manually adjusted in order to minimize surface glare. Only the raw camera files were used in the processing.

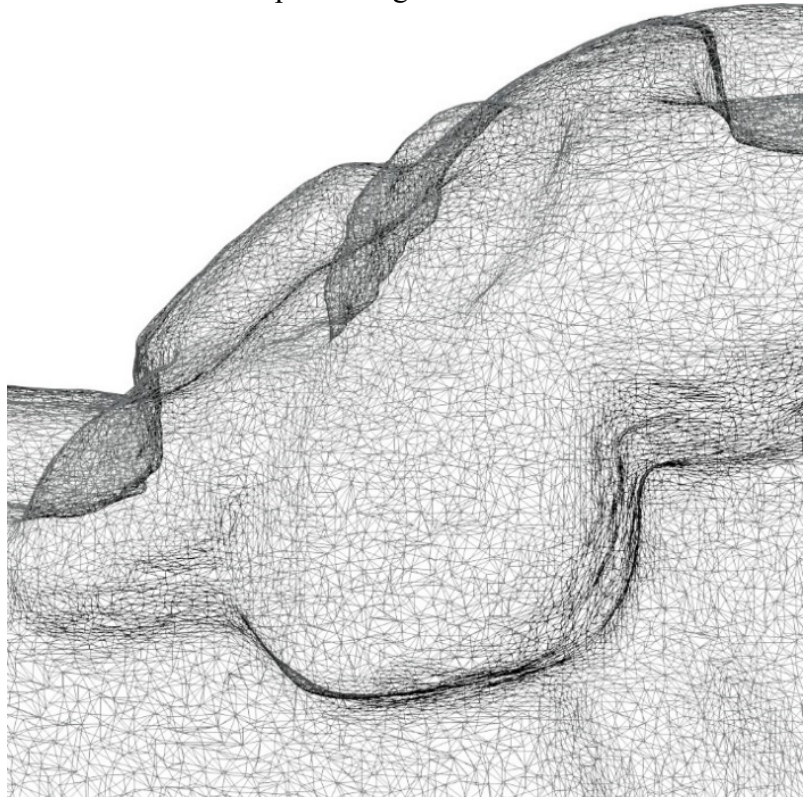

Figure 3. A 3D model of a rococo detail of the wooden chair frame.

Objects required 400 to over 1000 images to be taken in order to be sufficiently covered. A major pre-processing of some difficult surface parts had to be done. After several testing runs a semiautomated pre-processing routines were developed and employed in all cases. Since the objects were flipped between separate chunk scans, a systematic masking of the background was required. A standard desktop image processing packages were employed in this stage.

In most cases, the photogrammetric processing was done in two chunks as the objects had to be flipped in order to properly scan bottom areas. This method yielded best results in terms of object surface consistency and spatial fidelity.

The processing was done mostly in PhotoScan (PS) with some processing conducted in PhotoModeler (PM).

\subsection{Results}

The resulting $3 \mathrm{D}$ models were calculated with an average surface resolution (GSD) of $0.3 \mathrm{~mm}$ (Figure 3) while the resulting spatial accuracy was $\sim 0.5 \mathrm{~mm}$.

The final dense point clouds were in orders of tens of millions (up to $100 \mathrm{M}$ points), depending on the actual surface area and object size. Subsequently the mesh and texturized models were rather large (desk, sofa) and required high performance IT hardware for manipulation and display.

The digital model's level of surface details allowed historic furniture conservationists to study detailed morphology of separate furniture parts, to see single stokes of carver's hand, to analyze surface treatment materials (i.e. golden plating) state and aging processes as well as study and compare different styles of old carvers.

\section{SUBJECT: FOLK COSTUME}

A historic (archival) theatre male costume (Figure 4) was selected for scanning as a special recognition of the actor and popularity of the play it was used in. The final 3D model was to be used for public presentation purposes of the owner (Slovak National Theatre, Bratislava, Slovakia). Since a single camera sequential scanning was to be used, the project proved to be challenging given the particular setup and costume manipulation limitations. The final 3D model had to be as close to a model of a dressed person as possible.

The costume consisted of 6 parts (hat, top, trousers, wide belt, shoes and a long-handled axe).

\subsection{Preparations and technique}

The costume had to be put on and arranged on a dummy as the actor using the costume is deceased. A dedicated diffuse light tent was utilized while special lights arrangement was set up in order to achieve best light along the vertical object axis. The axe had to be scanned separately and then put in the hand of the dummy in a digital 3D post-processing.

Visible plastic surface of the dummy had to be dust treated to minimize flare.

A total of $4,200 \mathrm{~W}$ of lighting output was used to generate a controlled diffuse lighting conditions. Extra weighs had to be used in order to make the whole dummy setup more stable.

\subsection{Scanning and processing}

Scanning was done manually in a semi-cylindrical scanning pattern using hi-res DSLR cameras (i.e. Canon 5 D MkIII) in the tent. Some minor costume parts were scanned in separate batches to achieve higher detail and resolution.

Only the raw camera files were used in the processing. A major challenge was to keep the cloth surface stable/in place. A standard desktop image processing packages were employed in an image pre-processing. The photogrammetric processing was executed in a single chunk in PhotoScan. A stereoscopic (3D) video presentation was produced as a final form of delivery. 


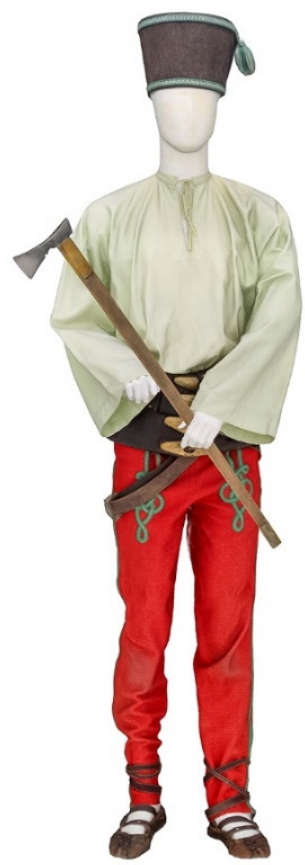

Figure 4. 3D model of a folk costume (2 models merged)

\subsection{Results}

Understandably, in this case the spatial accuracy requirement was not as stringent as with other types of object models. The resulting 3D model was developed to an average surface resolution (GSD) of $0.4 \mathrm{~mm}$.

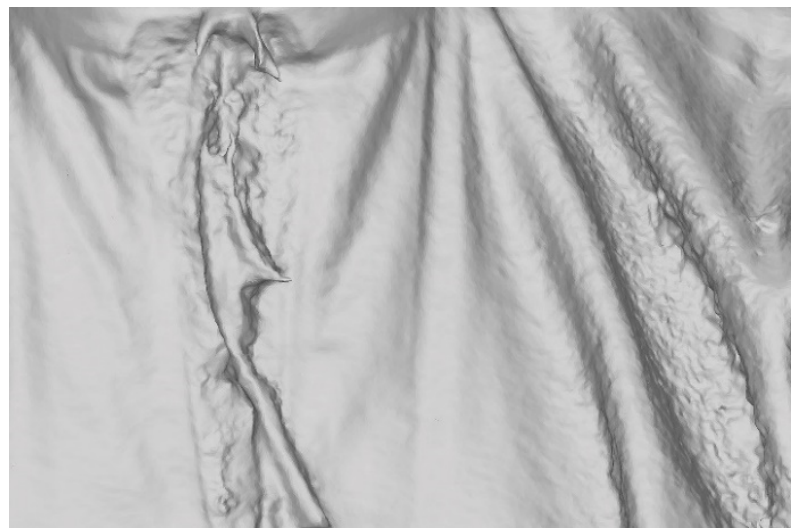

Figure 5. Detail of costume 3D model where details (laces, cloth folds) proved to be problematic due to lack of spatial separation and difficult accessibility.

The final model was digitally assembled from two separate models (body and the axe). It fully met the object owner's expectations and the project served as a benchmark and test example for further similar non-solid theatre stage object modelling.

\section{SUBJECT: INSECT SPECIMEN}

Many insect specimens existing in museums and insect archives are of extinct or very rare species. Others are unique to a specific location or continent and thus difficult to obtain for scientists far away. This led to many collections to be photographed, later digitally photographed and recently scanned in order to provide study material without physically sending the specimen itself. In case of 3D models, the details rendered and overall quality of the model strongly determine possibilities and depth of study scientists are subsequently able to attain.

As discussed in (Nguyen, 2014), there are several technical challenges to be addressed when attempting to scan relatively fragile objects of a several $\mathrm{mm}$ to few $\mathrm{cm}$ size. Approached by Slovak Academy of Sciences experts, we were tasked to give it a try with special intent of capturing fine details (legs, antennae) of the specimen.

\subsection{Preparations and technique}

The specimen of Spotted Flower Beetle (Stephanorrhina guttata, Figure 6) was mounted on a special holder of electronically controlled rotating head.

A dedicated diffuse box was prepared while many lighting setups were designed and tried. As many insect bear rather shiny surface, getting the lighting right and powerful enough to warrant required aperture setting was a challenge, but important.

Camera was then placed on a separate electronically tethered bench that was to provide change of focus plane without having to refocus using the lens electronic system (Figure 7).

A rather complex problems in areas of photographic optics, depth of field and coverage the object's surface geometry had to be addressed. The basic setup used in (Nguyen, 2014) was partially applied and modified in order to achieve improved high fidelity results.

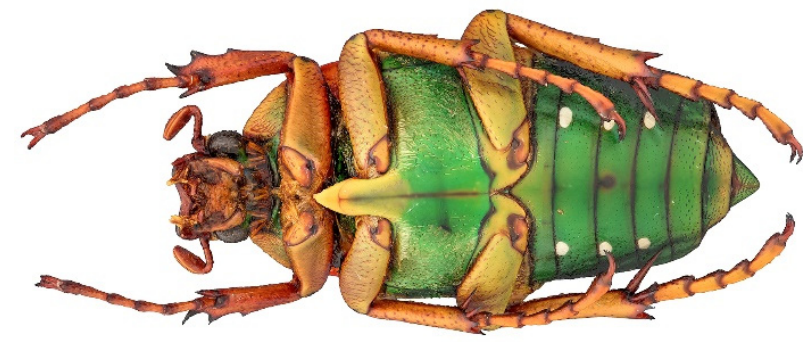

Figure 6. Textured 3D model of the Spotted Flower Beetle.

\subsection{Scanning and processing}

An automated scanning workflow was developed. In order to get the whole displayed insect surface in focus and prior to photogrammetric processing, every image has been preprocessed using image stacking software (usually comprising of around 15 shots). This resulted in 108 stacked images then used in PhotoScan for 3D processing.

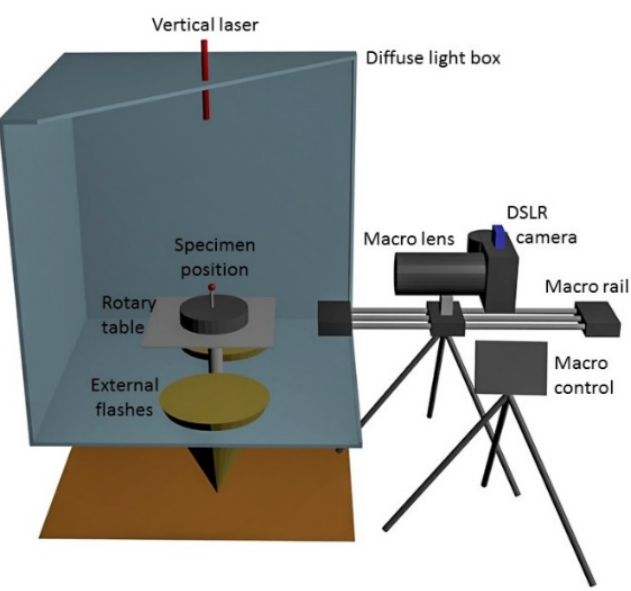

Figure 7. Schema of the macro scanning bench setup. 
The number of stack shots was calculated based on the total depth of field to be covered and the effective optical depth of a single shot. The theoretical figure was then verified and confronted in a series of trials as the geometric configuration of the particular shooting position (object against the lens optical axis) plays a major role in getting the two subsequent shots without any blur inbetween.

\subsection{Results}

After some fine tuning of the scanning process, the level of clear detail reached was $0.1 \mathrm{~mm}$ with finest discernible details going down to around $0.04 \mathrm{~mm}$. This in turn allowed a rather detailed morphology study of separate insect organs (Figure 8).

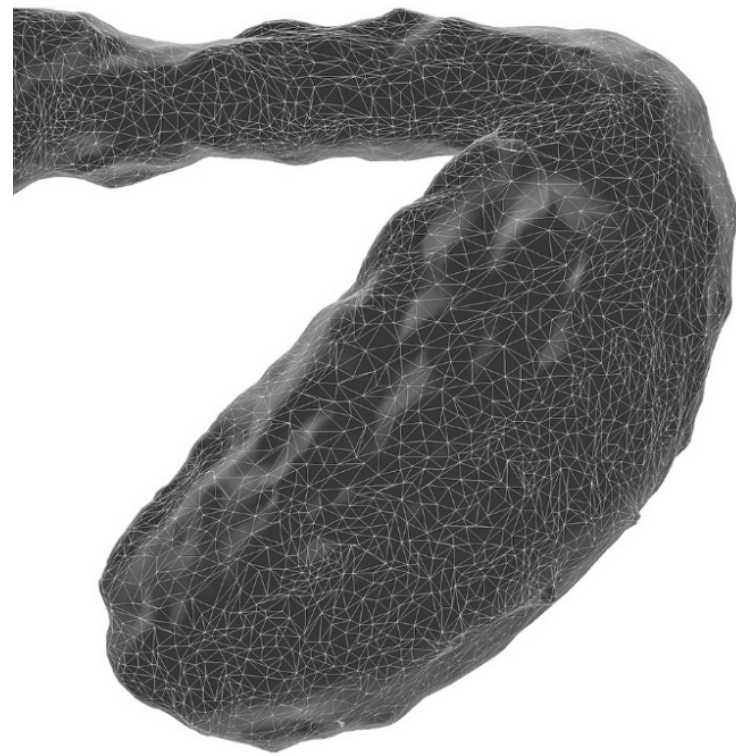

Figure 8. Detail of antenna of the 3D insect model illustrating the level of detail attained $(\sim 0.04 \mathrm{~mm})$.

\section{SUBJECT: SPIRAL STAIRCASE}

A planned reconstruction of given staircase was the leading reason for its metric documentation. Staircase (Figure 9) is located on the north side of the Saint Catherine church $\left(15^{\text {th }}\right.$ century) in Banská Štiavnica, Slovakia, a town on the UNESCO World heritage sites list. The staircase provides access to the chorus and the loft of the church and a little bell is located on top in the loft of the staircase. The stair tower is of about $20 \mathrm{~m}$ height and has 50 steps in 3.5 turns. The height of a single step is $25 \mathrm{~cm}$. The limited width of the staircase $(1 \mathrm{~m})$ is a major obstacle for laser scanning application. The surface of the walls and ceiling has rather flat and featureless texture of a white plaster while the steps are carved in tuff and andesite material rendering an ideal surface texture for image scanning.
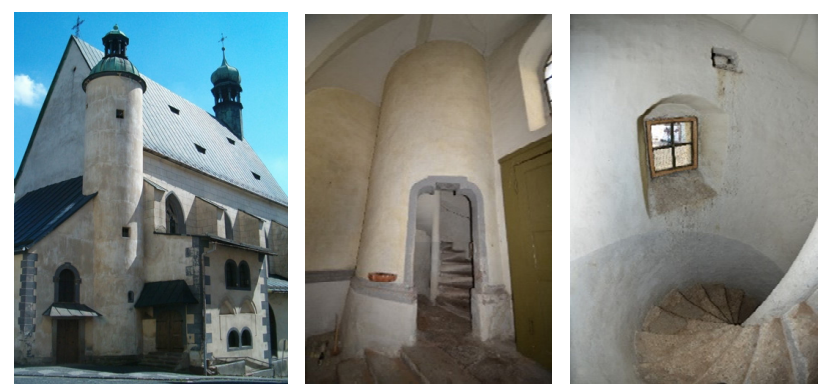

Figure 9. Exterior scene of staircase, entry and interior (from left to right)

\subsection{Preparations and technique}

No special scanning hardware adjustments were required other than utilization of fisheye/very wide angle lenses and external flash to improve the light conditions. Georeferencing of the model was done using points selected from laser scans of the upper part of interior and the entrance section. Before this, laser scans were georeferenced through points measured by a total station (from the window on the top and the door at the bottom). This approach ensured a solid spatial reference for matching of the photogrammetric model to the reference system.

\subsection{Scanning and processing}

Nikon D800E camera with AF Fisheye Nikkor $16 \mathrm{~mm} / \mathrm{f} 2.8$ lenses and Nikon D5100 with Tamron 10-24 mm lens were used for simultaneous scan from every step pointing up- and dowstairs. Overall some 400 images have been processed in PhotoScan and Reality Capture (RC) software, resulting in a point cloud of $40,000,000$ points (normal reconstruction mode). Outer staircase wall was scanned using laser scanning technology by Riegl VZ400 instrument.

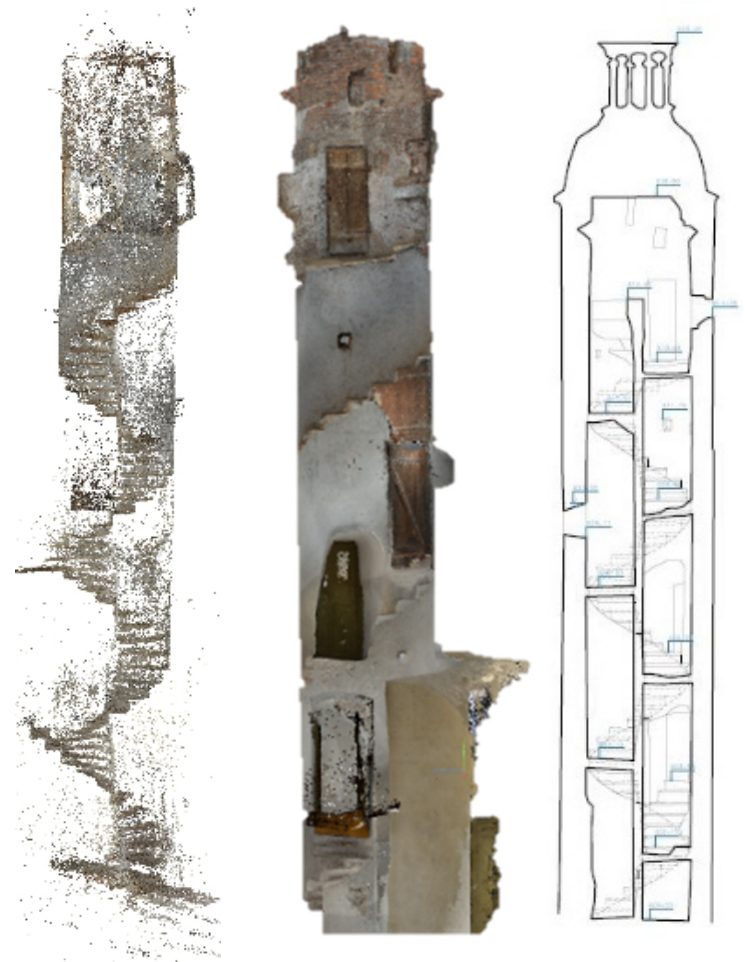

Figure 10. From left to right: Tie point cloud (PS sw), dense cloud (RC sw) and 2D draw of vertical model section

\subsection{Results}

The mesh 3D model generated from point cloud provided suitable base for required 2D metric drawing/documentation (Figure 10,11). The control points residuals (located at the top and bottom of the staircase only) didn't exceed $10 \mathrm{~mm}$. As a consequence of the object geometry and texture, this example presents a viable and efficient combination of both technologies - image based modelling and laser scanning.

In this case we didn't opt for laser scanning of the staircase interior due to the spatial difficulty of data acquisition as well as processing, specifically filed works time consumption, large number of laser scans required, very tight space around the scanner, steepness of the stairs, potential problems with automated merging of scans given the repetitive geometry, 
problematic measurement of control points etc. On the contrary, the exterior staircase wall was calling to be documented by a laser scanning, in detail, easily and quickly from just 3 observation points.

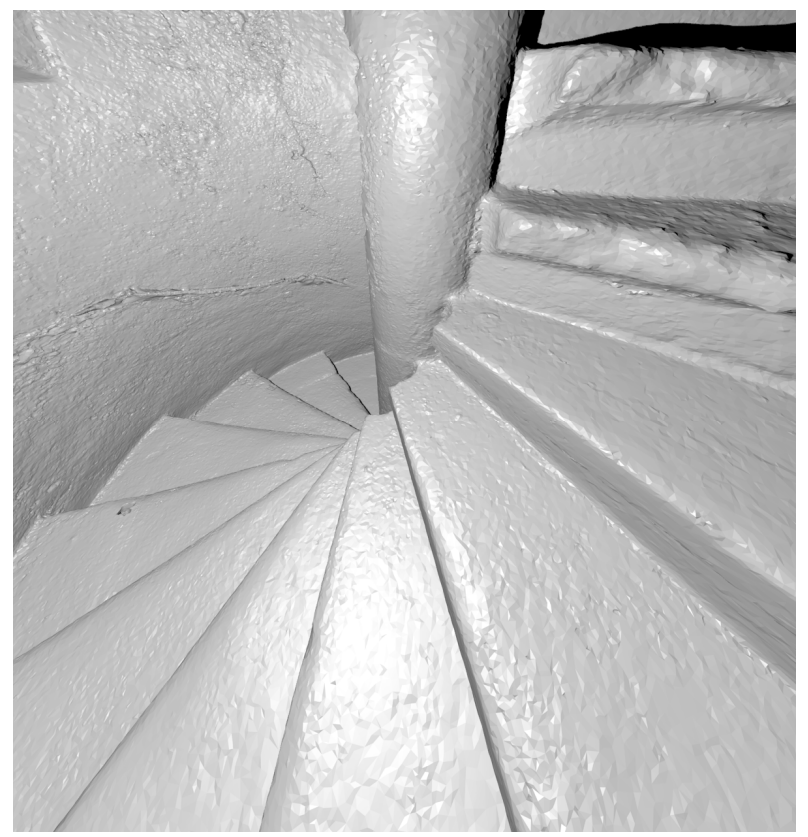

Figure 11. Rendered model of the staircase interior

\section{SUBJECT: WOODEN SKELETONS}

Wooden skeleton structures can be very complex and hard to access. Timber roof trusses or bell landings are sparse but spacious and multilevel constructions, therefore the laser scanning is a preferred method for its documentation. Various cases are documented in (Fregonese, 2009), (Balletti, 2003), (Koehl, 2013) or (Andrews, 2013). Following examples discuss application of image based modelling for metric documentation of such objects.

\subsection{Hussite bastion in Krupina}

The bastion (Figure 12) is one of the oldest objects in the town, it was built around the $15^{\text {th }}$ century and is a National heritage site (cultural monument). In the past 100 years it was rarely used, so an idea to reconstruct the object and create an ecclesiastical museum in it was developed.

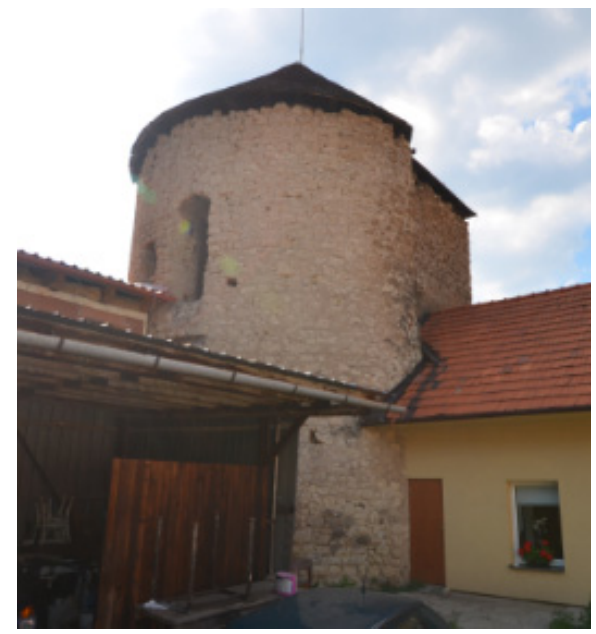

Figure 12. Hussite bastion, exterior view
The image based modelling was used to document the entire object with its 3 floors, exterior walls and wooden roof. The imagery of the truss was taken with two cameras - a mediumformat PhaseOne 645D camera with a Leaf Aptus II-7 digital back and a $45 \mathrm{~mm}$ 1:2.8 PhaseOne lens and a Nikon D5100 DSLR with Tamron DiII SP 10-24 mm 1:3.5-4.5 lens. The latter was used at a $10 \mathrm{~mm}$ focal length to get a sufficient overlap of the truss and interior walls that would then enable the processing of the whole interior in one block. This allowed for the reference coordinate system of the timber truss $3 \mathrm{D}$ model to be defined without terrestrially measured control points located directly on its construction. The control points were located on the interior walls and surveyed through windows from the outside using a total station. After the transformation of the entire object into the reference coordinate system, the residuals on these points were under $5 \mathrm{~mm}$.
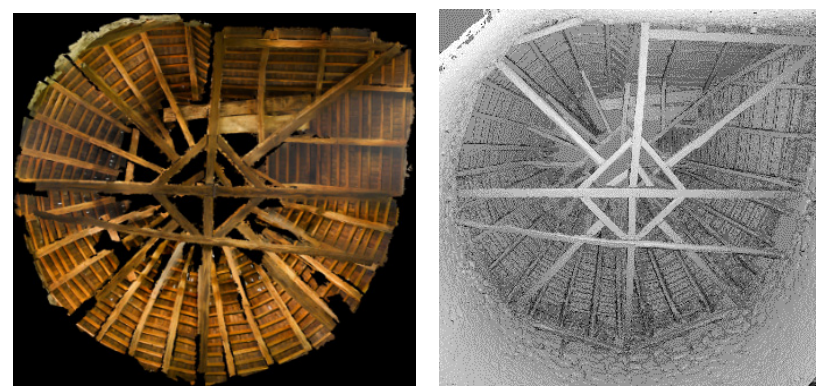

Figure 13. Orthophoto (left) and 3D model of the timber truss (right)

Upper sides of the beams were not digitally reconstructed since the resulting model (Figure 13) was sufficient for vector drawing documentation production. Eventually, it would be possible to cover upper parts too using telescopic tripod able to get the camera higher and between the beams.

\subsection{Belfry in Banská Štiavnica}

The Bell Hill is a geographical name for an area covering three cemeteries in Banská Štiavnica that is on recently discussed plans for its revitalization. This would include a $19^{\text {th }}$ century bell tower (Figure 14) reconstruction.

The object is approx. $12 \mathrm{~m}$ high tower structure. It contains a partially damaged wooden bell landing similar to the timber truss in its design. A complete set of digital blueprints of the interior and exterior was needed for the reconstruction project.

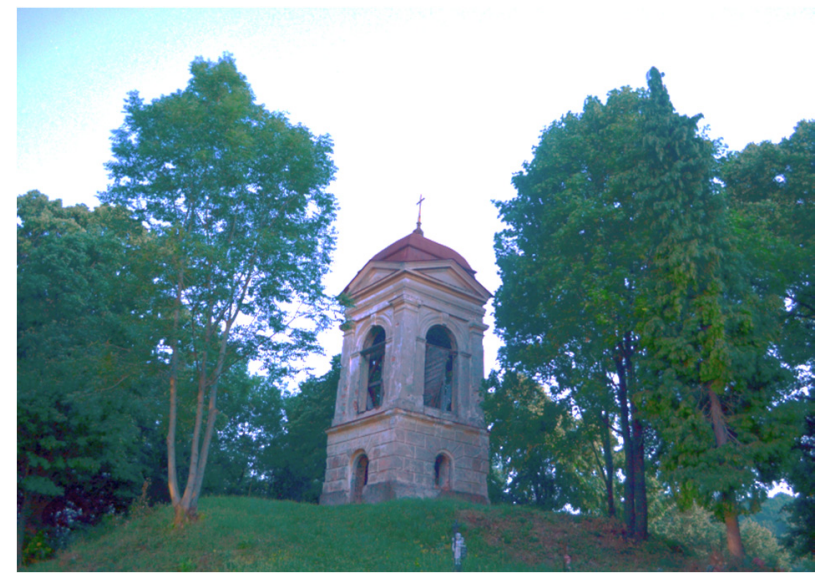

Figure 14. Belfry on the Bell hill

The location geometry was complicated by many factors: tower's surrounding (steep slope, tall vegetation), the tower's height, 
limited interior space $(2.8 \mathrm{~m})$, poor light conditions inside and the inner timber structure itself. The tower is surrounded by trees, thus the image recording had to be a rather close range one (ca 2 $\mathrm{m})$. This led to a wide angle lens being used. Camera used was a Nikon D5100 DSLR with a Tamron 10-24 mm lens. A telescopic tripod reaching up to $7 \mathrm{~m}$ high was used in the scanning prosecco (Figure 15). Part of the roof was scanned using a drone equipped with a GoPro Hero 4 camera, but using it for outer walls proved to be difficult due to the vegetation obstacles.

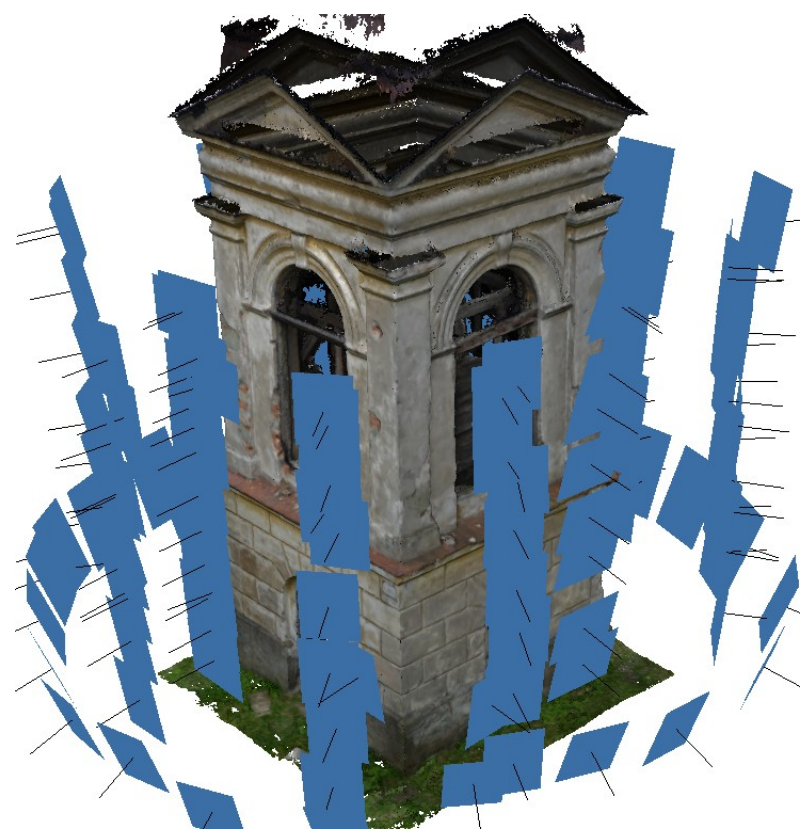

Figure 15. Image configuration using telescopic tripod (PS software)

The interior (Figure 16) scanning was conducted in a way so that all lower interior walls were covered and in overlap with the upper timber structure scans. The same $7 \mathrm{~m}$ high-reach tripod was used to reach upper spaces between the beams while keeping the incremental rise intervals constant. The tripod allowed for bottom side of the roof to be scanned too.

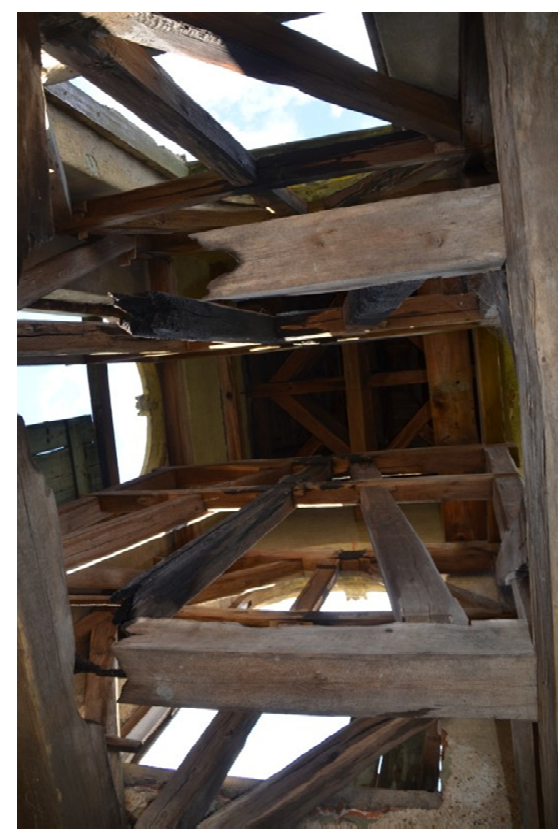

Figure 16. Bottom photo view of wooden bell landing

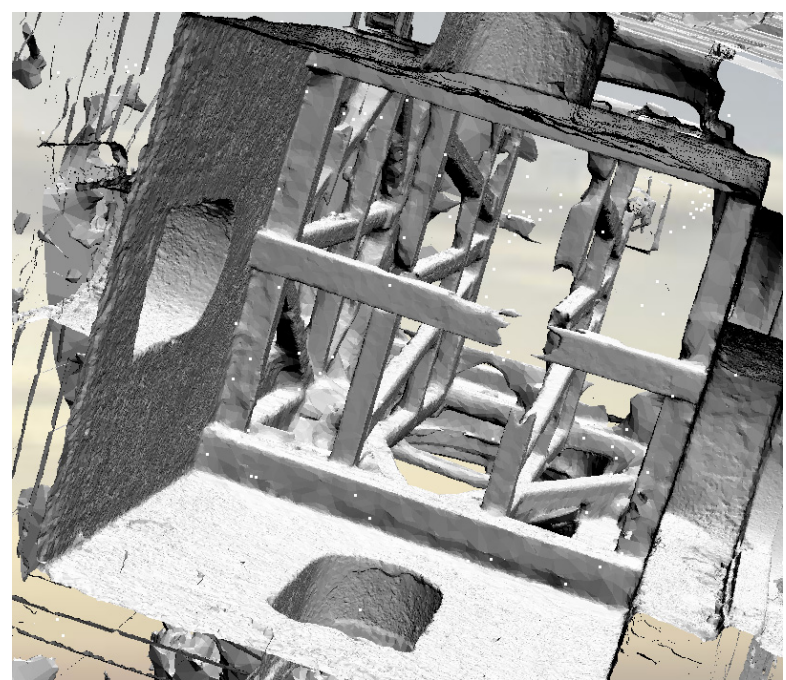

Figure 17. Partially damaged wooden bell landing - 3D model of bell landing (ContextCapture software)

The photogrammetric processing resulted in a $40 \mathrm{M}$ points strong 3D TIN model (Figure 18). The model was georeferenced using control point yielding residuals under $10 \mathrm{~mm}$ on check points, which is sufficient given the application. 3D model then served as source for production of various orthophotos and section views that were in turn utilized in a subsequent $2 \mathrm{D}$ vector documentation production (Figure 19, 20).

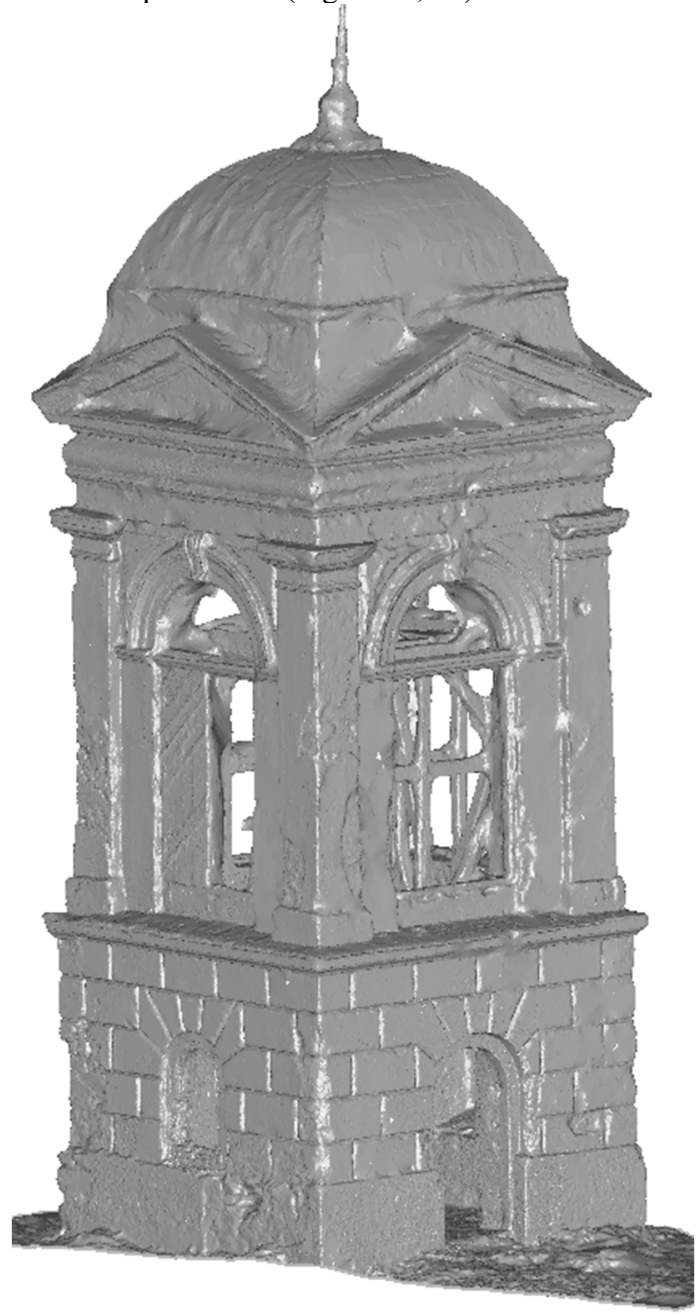

Figure 18. 3D model of belfry 


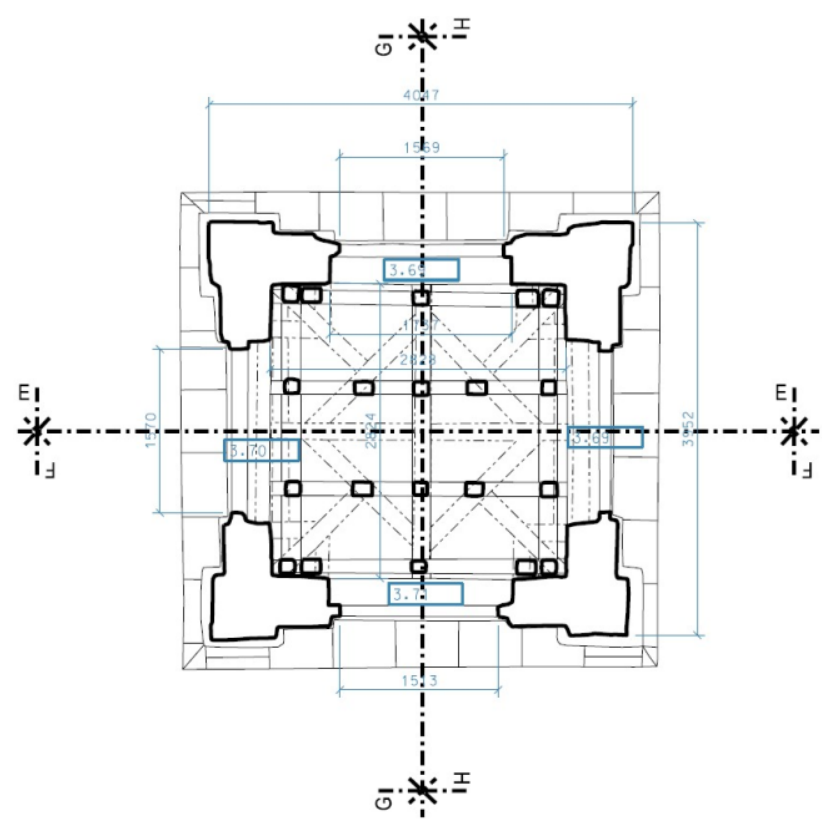

Figure 19. Horizontal section view

Usage of a total station for bell tower's exterior or interior documentation would prove to be ineffective due to the large amount of architectural details as well as view-obstructing overlaps of the interior timber structure. On the other hand, image based modelling conducted between the beams allowed for surfaces not visible from the ground and the bell landing to be recorded. Terrestrial laser scanning of the exterior would be close to impossible due to the vegetation, upper parts being obstructed (protruding façade details and such) and in the interior due to the view obstructions by the timber structure.

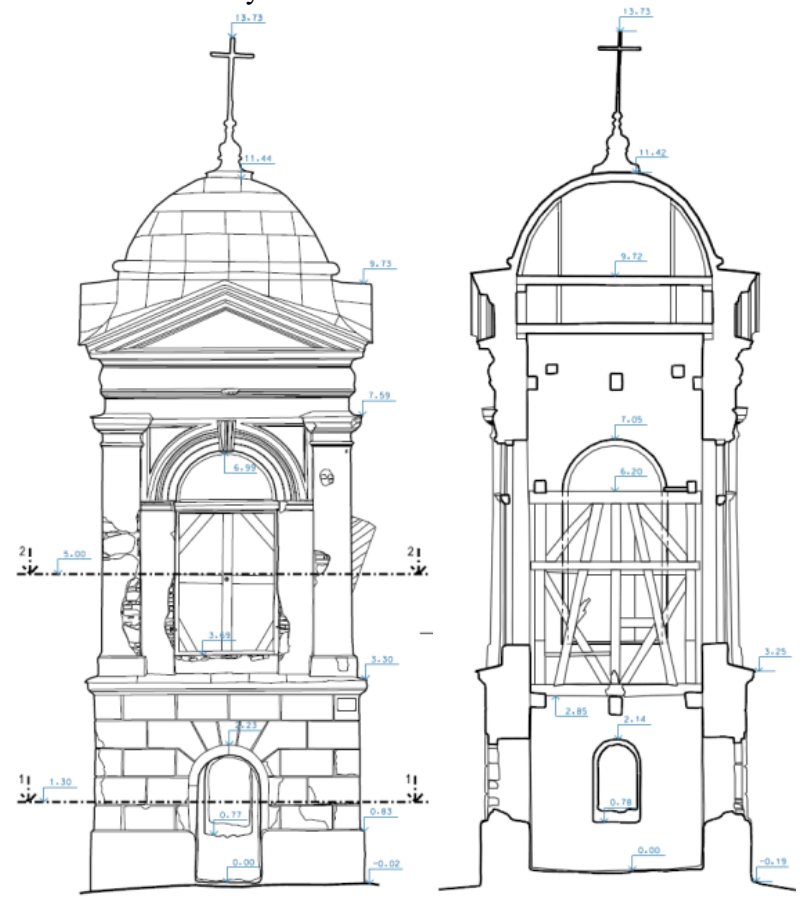

Figure 20. Vector plan of the exterior wall (left) and vertical section view (right)

\section{CONCLUSION}

In both cases, the cultural as well as natural heritage objects, a rigorous documentation process is required in order to provide outputs of a high spatial, radiometric and spectral resolutions while meeting the accuracy demands regardless of the object's size and shape complexity. The only surveying method that is able to cover all of these and is more flexible at field works end, is photogrammetry with its image based modelling techniques. Yet, given the wide scope of the subject matter, no technique is universal. And despite major progress recently made in the image based modelling methods area, there are limits or hindrances that can be overcome only by object's surface treatment to minimize glare, lighting and scanning distance and geometry conditioning or by bringing another scanning/surveying technique in (mostly laser scanning). Especially the geometry of the scanning process was thoroughly examined, experimented with and applied on various objects.

It is obvious that the scanning procedures are undergoing major changes too and advancements in moving platform scanning and continuous recording technology (hi speed video/imaging) may soon change the scanning paradigm again. But for the current state of affairs it is our conclusion that careful planning and tailoring of the scanning process' geometry even hard-to-access, obscured or very intricately shaped objects are able to be scanned and subsequently modelled using the image based techniques and workflows.

Also, different software processing tools render different levels of resistance against various texture, lighting and geometry issues while providing all sorts of advantages on the other hand (i.e. based on our experience, PhotoScan is very stable at image alignment, ContextCapture at sharp edge modelling or RealityCapture at processing speed).

Despite of a relatively high quality of the current output, it is very likely major improvements and new development in both the scanning and processing tools will occur while trying to keep and build on the best that is known and available now.

\section{ACKNOWLEDGEMENTS}

Authors would like to thank:

Bundesmobilienvewaltung, Vienna, Austria for granting access and permission to scan historic furniture originals

Eszterháza Chateau, Fertöd, Hungary for granting access and permission to scan historic furniture originals

Slovak National Theatre for providing assistance with the theatre folk costume arrangements

Slovak Academy of Sciences for provision of insect specimens and consulting

VEGA Slovak Grant Agency under projects No. 1/0133/14

\section{REFERENCES}

Andrews, D.P., Bedford, J., Bryan, P.G., 2013. A comparison of laser scanning and structure from motion as applied to the great barn at harmondsworth, UK. In: The International Archives of the Photogrammetry, Remote Sensing and Spatial Information Sciences, Volume XL-5/W2, 2013, XXIV International CIPA Symposium, 2 - 6 September 2013, Strasbourg, France

Balletti, C., Guerra, F., Gerbaudi, F., 2003. The survey of the wooden structure of the roof of palazzo ducale in venice. In: The International Archives of the Photogrammetry, Remote Sensing and Spatial Information Sciences, Vol. XXXIV, Part 5/W12, 1-3 July 2003, Ancona, Italy. 
Fassi, F., Fregonese, L., Ackermann, S., and De Troia, V., 2013. Comparison between laser scanning and automated 3D modelling techniques to reconstruct complex and extensive cultural heritage areas, In: The International Archives of the Photogrammetry, Remote Sensing and Spatial Information Sciences, XL-5/W1, 73-80, doi:10.5194/isprsarchives-XL-5W1-73-2013, 2013

Fregonese, L., Taffurelli, L., 2009. 3D model for the documentation of Cultural Heritage: the wooden domes of St.Mark's Basilica in Venice. In: ISPRS Archives - Volume XXXVIII-5/W1, 2009, WG V/4, 3D-ARCH 2009: "3D Virtual Reconstruction and Visualization of Complex Architectures", 25-28 February 2009, Trento, Italy

Koehl, M., Viale, A., and Reeb, S., 2013. A historical timber frame model for diagnosis and documentation before building restoration. In: ISPRS Ann. Photogramm. Remote Sens. Spatial Inf. Sci., II-2/W1, 201-212, doi:10.5194/isprsannals-II-2-W1201-2013, 2013.

Nguyen, C.V., Lovell D.R., Adcock, M., La Salle, J., 2014. Capturing Natural-Colour 3D Models of Insects for Species Discovery and Diagnostics. In: PLoS ONE 9(4): e94346. doi:10.1371/journal.pone.0094346.

Pavelka, K., Reznicek, J., Matouskova, E., Faltynova, M., 2014. RPAS as a tool for the research, documentation and monitoring. In: 35th Asian Conference on Remote Sensing 2014, ACRS 2014: Sensing for Reintegration of Societies, pp., SCOPUS 